\title{
Subventricular Zone Stem Cells Are Heterogeneous with Respect to Their Embryonic Origins and Neurogenic Fates in the Adult Olfactory Bulb
}

\author{
Kaylene M. Young, Matthew Fogarty, Nicoletta Kessaris, ${ }^{\star}$ and William D. Richardson ${ }^{\star}$ \\ Wolfson Institute for Biomedical Research and Department of Biology, University College London, London WC1E 6BT, United Kingdom
}

\begin{abstract}
We determined the embryonic origins of adult forebrain subventricular zone (SVZ) stem cells by Cre-lox fate mapping in transgenic mice. We found that all parts of the telencephalic neuroepithelium, including the medial ganglionic eminence and lateral ganglionic eminence (LGE) and the cerebral cortex, contribute multipotent, self-renewing stem cells to the adult SVZ. Descendants of the embryonic LGE and cortex settle in ventral and dorsal aspects of the dorsolateral SVZ, respectively. Both populations contribute new (5-bromo-2'deoxyuridine-labeled) tyrosine hydroxylase- and calretinin-positive interneurons to the adult olfactory bulb. However, calbindinpositive interneurons in the olfactory glomeruli were generated exclusively by LGE-derived stem cells. Thus, different SVZ stem cells have different embryonic origins, colonize different parts of the SVZ, and generate different neuronal progeny, suggesting that some aspects of embryonic patterning are preserved in the adult SVZ. This could have important implications for the design of endogenous stem cell-based therapies in the future.
\end{abstract}

Key words: adult; mouse; subventricular zone; neural stem cells; olfactory bulb; interneurons; Cre-lox fate mapping; Gsh2; Emx1

\section{Introduction}

Since the identification of neural stem cells in the adult forebrain subventricular zone (SVZ) (Reynolds and Weiss, 1992; Richards et al., 1992), a lot of work has been done to characterize the phenotype of these stem cells, the SVZ cytoarchitecture, and factors involved in regulating stem cell maintenance and behavior (for review, see Gage, 2000; Doetsch, 2003; Alvarez-Buylla and Lim, 2004; Morshead and van der Kooy, 2004; Young et al., 2007). Adult neural stem cells have been described as a subpopulation of SVZ astrocytes because of their morphology and the fact that they express the astrocyte marker, glial fibrillary acidic protein (GFAP) (Doetsch et al., 1999a; Laywell et al., 2000). It is now well established that the slowly dividing SVZ stem cells generate rapidly dividing neuronal progenitors (transit amplifying cells) that in turn generate postmitotic neuroblasts. These migrate forwards along the rostral migratory stream (RMS) into the olfactory bulb, where they give rise to various subtypes of olfactory interneurons continuously throughout life (for review, see Lledo

Received Feb. 2, 2007; revised June 6, 2007; accepted June 7, 2007.

This work was supported by the United Kingdom Medical Research Council (MRC) and the Wellcome Trust (Functional Genomics Initiative). N.K. is the recipient of an MRC New Investigator Award, and M.F. was a Wellcome Trust Prize student. We thank our colleagues in the Wolfson Institute for Biomedical Research (University College London) for helpful comments and discussion. Ulla Dennehy and Matthew Grist provided outstanding technical help. We thank Shankar Srinivas for providing the R26R-YFP mice, Kenneth Campbell for a gift of anti-Gsh2 antibody, and Derek van der Kooy and Sandrine Willaime-Morawek for communicating data before publication.

*N.K. and W.D.R. contributed equally to this work.

Correspondence should be addressed to William D. Richardson, Wolfson Institute for Biomedical Research and Department of Biology, University College London, Gower Street, London WC1E 6BT, UK. E-mail: w.richardson@ucl.ac.uk.

DOI:10.1523/JNEUROSCI.0476-07.2007

Copyright $\odot 2007$ Society for Neuroscience $\quad$ 0270-6474/07/278286-11\$15.00/0 et al., 2006). However, it is still unclear whether the SVZ contains a heterogeneous collection of neural stem cells with different neurogenic potentials or whether cell fate restriction occurs later, within the RMS or the olfactory bulb.

Neuroepithelial precursors in most parts of the embryonic telencephalon have a similar radial morphology and express antigenic markers characteristic of radial glia (Noctor et al., 2002; Malatesta et al., 2003; Anthony et al., 2004). However, there are also regional differences in gene expression, including regionally restricted expression of transcription factors (Kriegstein and Götz, 2003). For example, the medial ganglionic eminence (MGE) expresses Nkx2.1, the MGE and the lateral ganglionic eminence (LGE) express Gsh2, the corticostriatal sulcus expresses Dbx1, and the developing cortex expresses Emx1. As development proceeds, the neuroepithelial germinal zone [ventricular zone (VZ)] regresses and a relatively small proportion of neural stem cells persists in the SVZ of the adult forebrain. The relative contributions of different parts of the embryonic VZ to the adult SVZ have not yet been established, although the bulk of evidence suggests that adult stem cells are descendants of the LGE (embryonic striatum). For example, transcription factors that are expressed in the dorsal LGE of the embryo, such as Dlx1/2, Er81, Gsh2, and Pax6, are also present within the adult SVZ and RMS (Parmar et al., 2003; Stenman et al., 2003; Kohwi et al., 2005). In addition, viral lineage tracing of radial glia in the perinatal LGE has demonstrated that some of the progeny of these cells come to reside in the postnatal SVZ and contribute significantly to the adult neurosphere-forming activity (Merkle et al., 2004). Recent evidence supports the contribution of embryonic cortical (Emx1 -expressing) progenitors to generating the adult SVZ (Tamamaki, 2005; Willaime-Morawek et al., 2006; Ventura and Gold- 
man, 2007). However, it is still unknown whether other parts of the embryonic VZ such as the MGE contribute cells to the adult SVZ or, if so, whether adult SVZ cells retain their previously established positional and functional identities into adulthood.

Here, we have examined the origins of adult SVZ stem cells by Cre-lox fate mapping of the embryonic telencephalic neuroepithelium, using Nkx2.1-Cre, Gsh2-Cre, Dbx1-Cre, Emx1-Cre, and $E m \times 1-C r e E R^{T 2}$ transgenic mice (Fogarty et al., 2005; Kessaris et al., 2006). We found that the MGE, LGE, and the embryonic cortex all generate cells that populate different parts of the adult SVZ and exhibit the in vitro characteristics of multipotent neural stem cells. Both the LGE- and cortex-derived stem cells generate RMS neuroblasts and are responsible for generating olfactory interneurons throughout life. However, these two stem cell populations make unequal contributions to adult neurogenesis. Cortex-derived stem cells, despite being the minority, generate the majority of calretinin-positive interneurons but none of the calbindin-positive interneurons. LGE-derived stem cells generate all of the adult-born calbindin-positive interneurons for the olfactory glomerulus.

\section{Materials and Methods}

Transgenic mice. The generation and genotyping of Nkx2.1-Cre, Gsh2Cre, Emx1-Cre, Dbxl-Cre, and Emx1-CreER ${ }^{T 2}$ mice were described previously (Fogarty et al., 2005; Kessaris et al., 2006). Each transgenic line was crossed with either of two Cre reporter lines: Rosa26-enhanced green fluorescent protein (R26-GFP) (Mao et al., 2001) (The Jackson Laboratory, Bar Harbor, ME) or Rosa26-yellow fluorescent protein (R26-YFP) (Srinivas et al., 2001) (kindly provided by S. Srinivas, Oxford, UK). To activate Cre recombinase activity in $E m \times 1-C r e E R^{T 2} / R 26-Y F P$ transgenics (Kessaris et al., 2006), we administered tamoxifen (Sigma, St. Louis, $\mathrm{MO}$ ), dissolved by sonication at a concentration of $50 \mathrm{mg} / \mathrm{ml}$ in corn oil (Sigma). Induction at embryonic day 10.5 (E10.5) was performed using a single $4 \mathrm{mg}$ dose of tamoxifen administered into the stomach of pregnant mothers by gavage. Induction in adult mice was achieved by administering $300 \mathrm{mg} / \mathrm{kg}$ tamoxifen per day by gavage on 5 consecutive days.

5-Bromo-2'-deoxyuridine labeling. To identify cells dividing in vivo, 5-bromo-2'-deoxyuridine (BrdU) (Sigma) was dissolved in PBS by sonication to a concentration of $20 \mathrm{mg} / \mathrm{ml}$ and was administered as four $2 \mathrm{mg}$ intraperitoneal doses over 24 h (6:00 P.M., midnight, 6:00 A.M., noon).

Tissue preparation. Tissue was prepared as described previously (Young et al., 2007). Briefly, postnatal and adult mice [older than postnatal day 50 (P50)] were anesthetized with pentobarbitone and perfused through the ascending aorta, first with PBS and then with $4 \%(\mathrm{w} / \mathrm{v})$ paraformaldehyde (PFA) (Sigma) in PBS. Brains were removed, immersed in fresh $4 \% \mathrm{PFA}$, and stored at $4^{\circ} \mathrm{C}$ overnight. Tissue was cryoprotected in $20 \%$ (w/v) sucrose in PBS for $24 \mathrm{~h}$. All brains were embedded in OCT (optimal cutting temperature) compound, and coronal cryosections (15 or $30 \mu \mathrm{m}$ nominal thickness) were collected onto Superfrost Plus slides (BDH Chemicals, Poole, UK) or floated in PBS.

Neurosphere culture. Brains were removed and examined under an inverted fluorescence microscope to confirm GFP expression. Neurosphere cultures were subsequently generated from the SVZ of 7- to 8 -week-old (P50; young adult) mice by culturing in serum-free medium (Stem Cell Technologies, Vancouver, British Columbia, Canada) containing the mitogens epidermal growth factor (EGF) (Sigma) and basic fibroblast growth factor (bFGF) (Roche), as described previously (Reynolds and Weiss, 1992; Young et al., 2006, 2007). Primary cell suspensions were plated at clonal density (one cell per well) or at a density not exceeding 3500 cells $/ \mathrm{cm}^{2}$, and all cultures were maintained at $37^{\circ} \mathrm{C}$ in a $5 \% \mathrm{CO}_{2}$ atmosphere. Neurospheres were considered mature when they had reached an average diameter of $120 \mu \mathrm{m}$.

Expression of GFP in neurospheres was examined using an inverted fluorescence microscope at 6-7 d after plating. The number of GFPpositive neurospheres in each culture was scored and expressed as a percentage of the total. At day 7, a portion of the neurosphere culture was taken to test differentiation potential and the remainder was passaged.
Neurospheres were differentiated by plating onto glass coverslips precoated with poly-D-ornithine (Sigma) and cultured in DMEM/F12 medium (Invitrogen, Carlsbad, CA) with B27 supplement (Invitrogen) and $2 \%$ fetal calf serum (Invitrogen) for $5 \mathrm{~d}$. Differentiated neurospheres were fixed for $10 \mathrm{~min}$ in $4 \%$ PFA at room temperature, washed three times with PBS, and stored at $4^{\circ} \mathrm{C}$ for immunostaining. The remainder of the culture was passaged by enzymatic dissociation with trypsin/EDTA (Invitrogen) to generate a single-cell suspension, replated at a density of $10^{4}$ cells $/ \mathrm{cm}^{2}$, and serially passaged seven times or more.

Stem cell colony-forming assays. The proportion of neural stem cells originating from each region of the embryonic neuroepithelium was quantified using the Neurocult Neural Colony-Forming Cell Assay kit (Stem Cell Technologies) according to the manufacturer's instructions. In brief, a single-cell suspension was generated from the SVZ of each Cre-transgenic. The cells were mixed with NeuroCult NCFC Serum-Free Medium (Stem Cell Technologies), containing $20 \mathrm{ng} / \mathrm{ml} \mathrm{EGF} \mathrm{(Sigma),} 10$ $\mathrm{ng} / \mathrm{ml}$ bFGF (Roche), $3.5 \mu \mathrm{g} / \mathrm{ml}$ heparin (Sigma), and 30\% (v/v) collagen solution (Stem Cell Technologies). The suspension was poured into three $35 \mathrm{~mm}$ plates per mouse and incubated for 3 weeks at $37^{\circ} \mathrm{C}$ in a $5 \%$ $\mathrm{CO}_{2}$ atmosphere. Growth factors were replenished weekly. By the end of 3 weeks, $\sim 5 \%$ of colonies were $\geq 2 \mathrm{~mm}$ in diameter

Each plate was fixed with $4 \%$ PFA for $45 \mathrm{~min}$ at room temperature, and then washed three times with PBS. The collagen matrix was removed from the $35 \mathrm{~mm}$ dishes and placed into a $100 \mathrm{~mm}$ Petri dish (three into one) containing $10 \mathrm{ml}$ of blocking solution [PBS containing $0.1 \%(\mathrm{v} / \mathrm{v})$ Triton X-100, 10\% (v/v) normal sheep serum (Sigma)] and placed on an orbital shaker at room temperature for $3 \mathrm{~h}$. The blocking solution was replaced with $10 \mathrm{ml}$ of blocking solution containing rabbit anti-GFP (1:6000; Abcam, Cambridge, MA) and placed on a shaking platform overnight at $4^{\circ} \mathrm{C}$. Matrices were washed in PBS during the day and stained with Alexa Fluor 488-conjugated goat anti-rabbit IgG (1:1000; Invitrogen) overnight at $4^{\circ} \mathrm{C}$. Matrices were again washed in PBS for $4 \mathrm{~h}$ at room temperature before colony size was measured using a gridded Petri dish (Stem Cell Technologies). The neural stem cell colonies were characterized as $\geq 2 \mathrm{~mm}$ in diameter (B. Reynolds, unpublished data) (Bull and Bartlett, 2005) and scored as GFP positive or negative under a fluorescence dissecting microscope.

Immunocytochemistry. For GFP immunolabeling, sections were washed with PBS and permeabilized with blocking solution containing Triton X-100 and NGS (see above, Stem cell colony-forming assays) before incubating overnight with rabbit anti-GFP (1:6000) or rat antiGFP IgG2a (1:1000; Nacalai Tesque, Kyoto, Japan). Sections were washed three times with PBS before adding Alexa Fluor 488-conjugated antirabbit IgG or Alexa Fluor 488-conjugated anti-rat IgG (1:1000; Invitrogen) in blocking solution. Sections were treated with Hoechst 33258 $\left(1: 10^{4}\right.$; Sigma) to detect cell nuclei and washed with PBS. Floating sections $(30 \mu \mathrm{m})$ were transferred onto glass slides and mounted using Fluoromount (DakoCytomation, High Wycombe, UK). Sections were costained with Cy3-conjugated mouse anti-GFAP (1:3000; Sigma), rabbit anti-GFAP (1:500; DakoCytomation), mouse anti-neuronal-specific nuclear protein (NeuN) (1:500; Chemicon, Temecula, CA), rabbit anticalbindin (1:1000; Swant, Bellinzona, Switzerland), rabbit anti-calretinin (1:1000; Swant), rabbit anti-parvalbumin (1:1000; Chemicon), rabbit anti-tyrosine hydroxylase (1:1000; Chemicon), guinea pig antidoublecortin (1:3000; Chemicon), mouse anti-polysialylated neural cell adhesion molecule (PSA-NCAM) IgM (1:1000; Chemicon), or rabbit anti-Gsh2 polyclonal (1:2000; kind gift from Kenneth Campbell, University of Cincinnati, Cincinnati, OH) and detected with Alexa Fluor 568conjugated anti-mouse IgG1, Alexa Fluor 568-conjugated anti-rabbit IgG, Alexa Fluor 568-conjugated anti-mouse IgM (Invitrogen; all used at 1:1000), or Cy3-conjugated anti-guinea pig (1:500; Pierce, Rockford, IL).

For BrdU labeling to determine the identity of newly born cells, $30 \mu \mathrm{m}$ floating sections were first stained as above to detect GFP expression (or other listed antigens). The sections were subsequently collected onto glass slides and fixed with $70 \%$ ethanol/20\% glacial acetic acid and treated for a further $20 \mathrm{~min}$ with $70 \%$ ethanol at $-20^{\circ} \mathrm{C}$. Slides were then washed with $\mathrm{PBS} / 1 \%$ Triton X-100 (v/v) and acid treated with $6 \mathrm{M}$ $\mathrm{HCl} / 1 \%$ Triton $\mathrm{X}-100$ in PBS for 15 min before washing in PBS and staining with anti-BrdU [1:15; American Type Culture Collection (Ma- 
nassas, VA) mouse hybridoma], detected with Alexa Fluor 568-conjugated anti-mouse IgG1 or Alexa Fluor 647-conjugated anti-mouse IgG1 (1:1000; Invitrogen).

Protein colocalization (multiple fluorochromes) was assessed in the confocal microscope. Three mice were examined for each transgenic genotype. From each mouse, three $30 \mu \mathrm{m}$ coronal brain sections (i.e., six olfactory bulb sections) were immunolabeled to count calretinin/BrdU/GFP triple-positive cells or tyrosine hydroxylase/BrdU/GFP-positive cells, or $1030 \mu \mathrm{m}$ coronal sections (20 olfactory bulb sections) for calbindin/BrdU/GFP. A minimum of 20 newly born $\left(\mathrm{BrdU}^{+}\right)$neurons of each subtype (tyrosine hydroxylase, calretinin, or calbindin positive) were scored for GFP expression (see Fig. 7I). The proportions of BrdU- or calbindin-positive cells in the olfactory bulb were also examined solely for GFP coexpression (minimum of 300 positive cells per mouse) (Figs. 5H, $7 \mathrm{~J}, \mathrm{~K}$ ). Statistical comparisons were made by ANOVA (for multiple variables) or $t$ test (for single variables).

To determine whether GFP-positive neurospheres could generate multipotent progeny, neurospheres were cultured on coverslips under differentiating conditions and were double labeled (Young et al., 2006, 2007) with antirabbit GFP and one of the following: mouse anti- $\beta$ III-tubulin (1:2000; Promega, Madison, WI), rabbit anti-GFAP-Cy3 (1:2500; Sigma), mouse anti-GFAP (1:1500; Sigma), monoclonal O4 IgM (1:5; American Type Culture Collection mouse hybridoma). Sections were poststained with Hoechst 33258 nuclear stain (1: $10^{4}$; Sigma). Fixed coverslips were treated with blocking solution (as above) for $30 \mathrm{~min}$ at $37^{\circ} \mathrm{C}$, before the addition of the primary antibodies. The coverslips were washed three times with PBS before the addition of the appropriate secondary antibodies for $3 \mathrm{~h}$ at room temperature. Secondary antibodies included Alexa 568conjugated goat anti-mouse IgG1 (1:1000; Invitrogen), Alexa 680-conjugated goat antimouse IgM (1:1000; Invitrogen), and Alexa 488-conjugated goat anti-rabbit IgG (1:1000; Invitrogen). Coverslips were washed and mounted as above.

\section{Results}

The embryonic LGE and cortex both contribute cells to the adult SVZ

To map the contributions of different regions of the embryonic telencephalic VZ to the adult forebrain SVZ, we made use of a battery of transgenic lines that express Cre-recombinase in defined neuroepithelial domains: $N k x 2.1$-Cre (to label the MGE), Gsh2-Cre (LGE and MGE), Emx1Cre (cerebral cortex), and Dbx1-Cre (corticostriatal sulcus) (Fogarty et al., 2005; Kessaris et al., 2006) (Fig. 1O, E12). Each individual line (or combined $E m \times 1 / D b \times 1$ ) was crossed to the Cre-dependent R26GFP reporter line to label specific subsets of neuropithelial cells and all of their progeny in the embryonic and postnatal brain.
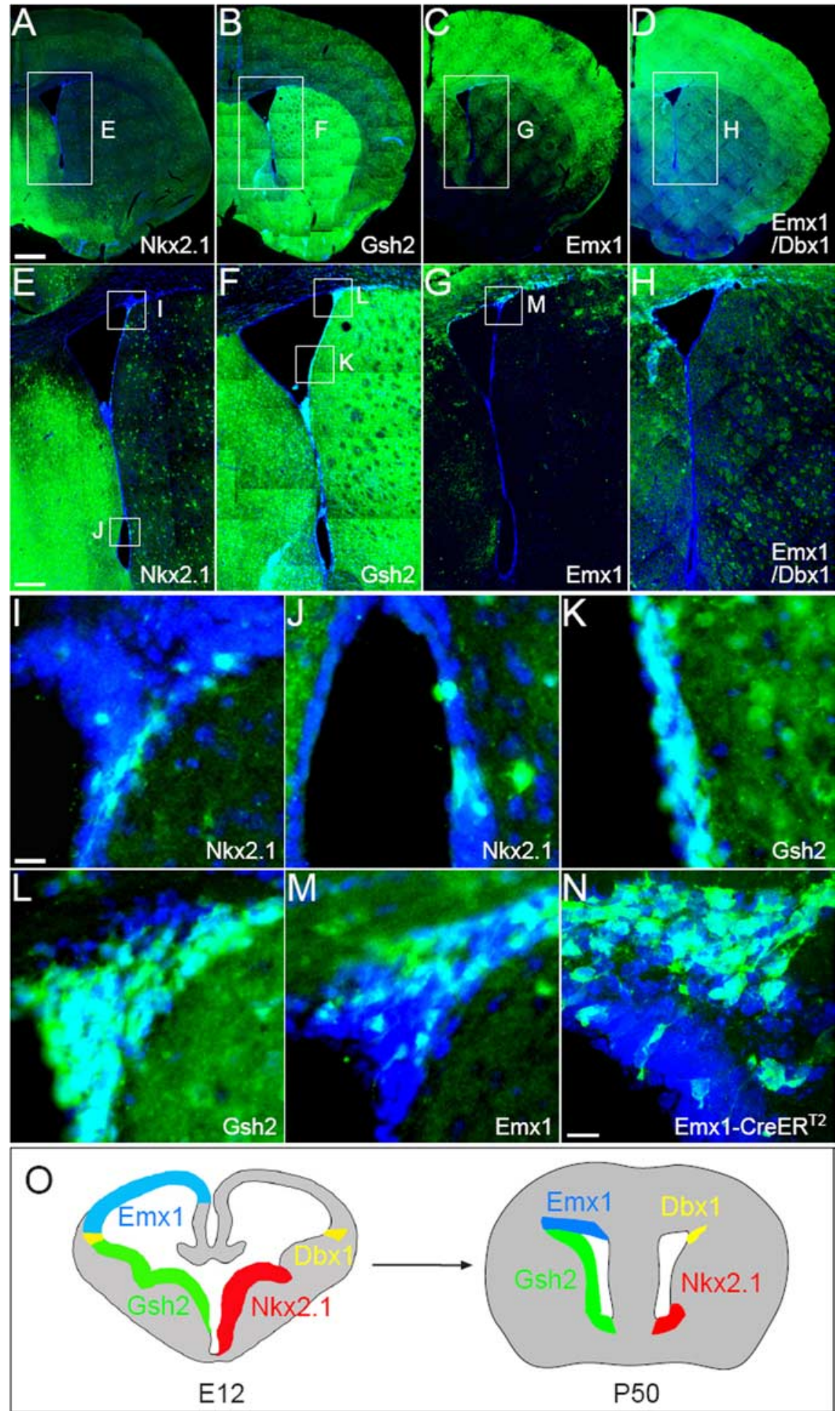

Figure 1. All regions of the telencephalic neuroepithelium contribute to the adult SVZ. Coronal sections ( $30 \mu \mathrm{m})$ of adult (P50) mouse brains were stained with rabbit anti-GFP (green) and Hoechst 33258 to visualize cell nuclei (blue). GFP-positive cells were detected by immunolabeling in sections from R26-GFP reporters carrying Nkx2.1-Cre $(\boldsymbol{A}, \boldsymbol{E})$, Gsh2-Cre $(\boldsymbol{B}, \boldsymbol{F})$, Emx1-Cre (C, $\boldsymbol{G})$, or Emx1/Dbx1-Cre $(\boldsymbol{D}, \boldsymbol{H})$ transgenes. Each region of the embryonic neuroepithelium contributed preferentially to distinct regions of the adult SVZ. Images (I-M) are higher-magnification confocal images of the areas boxed in $\boldsymbol{E}-\boldsymbol{H}$.I, J, Nkx2.1-Cre/R26-GFP brain. Groups of GFP-positive cells were occasionally detected at the ventral edge of the dorsolateral corner of the SVZ (I), as well as the ventral region of the lateral wall $(\boldsymbol{J}) . \boldsymbol{K}, \boldsymbol{L}$, GSh2-Cre/R26-GFP brain. Many GFP-positive cells were found in the lateral wall $(\boldsymbol{K})$ and the dorsolateral corner ( $\boldsymbol{L}$ ) of the SVZ. $\boldsymbol{M}$, Emx1-Cre/R26-GFP brain. Significant numbers of GFP-labeled cells are present, mainly in the dorsal half of the dorsolateral corner of the SVZ. N, Adult (P50) Emx1-CreER ${ }^{T 2} / R 26-Y F P$ brain, after tamoxifen induction at E10.5. The distribution of GFP-labeled cells was found to be similar to the Emx1-Cre/R26-GFP animals (i.e., in the dorsal part of the dorsolateral corner of the SVZ). 0 , Schematic depicting the different embryonic neuroepithelial domains targeted by our (re mice and their relative contribution to generating the adult SVZ. Scale bars: $A-D, 1 \mathrm{~mm} ; \boldsymbol{E}-\mathbf{H}, 0.5 \mathrm{~mm} ; \boldsymbol{I}-\mathbf{N}, 25 \mu \mathrm{m}$. 


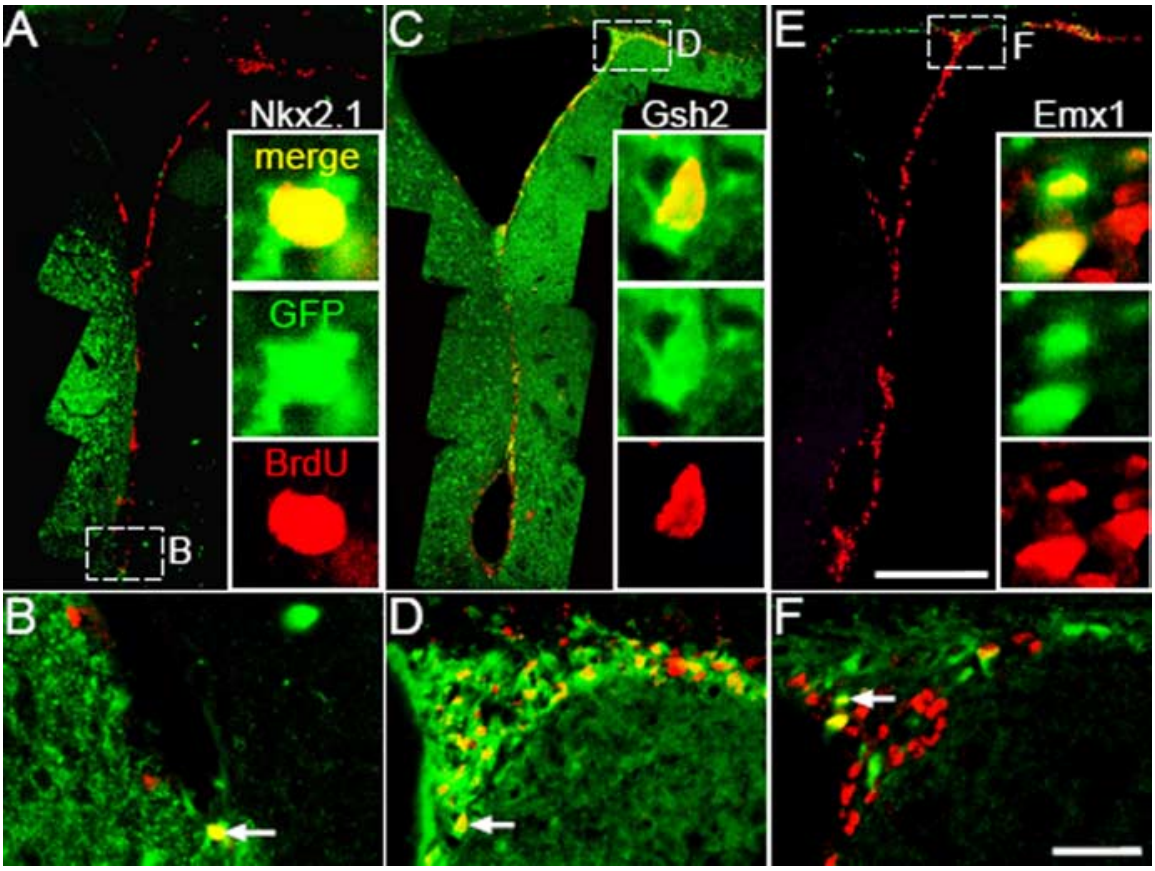

Figure 2. The embryonic striatum and cortex both contribute proliferative cells to the adult SVZ. BrdU was administered to adult R26-GFP reporter mice carrying Nkx2.1-Cre $(\boldsymbol{A}, \boldsymbol{B})$, Gsh2-Cre $(\boldsymbol{C}, \boldsymbol{D})$, or Emx1-Cre $(\boldsymbol{E}, \boldsymbol{F})$ transgenes, and the brains were analyzed $24 \mathrm{~h}$ later by immunolabeling with anti-BrdU (red) and anti-GFP (green) and confocal fluorescence microscopy. BrdU/ GFP double-positive cells (yellow) were present in all animals, the greatest proportion being found in Gsh2-Cre/R26-GFP mice. The inset high-magnification images are of the cells indicated by arrows $(\boldsymbol{B}, \boldsymbol{D}, \boldsymbol{F})$. All images are single confocal scans. Scale bars: $\boldsymbol{A}-\boldsymbol{C}$, $0.5 \mathrm{~mm} ; \boldsymbol{D}-\boldsymbol{F}, 50 \mu \mathrm{m}$.

Immunolabeling for GFP identified a significant contribution of cells from all parts of the embryonic neuroepithelium to the adult brain (Fig. $1 A-H)$. The $N k x 2.1$ domain (MGE) made a minor contribution to the adult SVZ, with the greater number of GFPpositive cells being located near the ventral extremity of the lateral ventricle (Fig. $1 E, J$ ). In occasional sections, cells were also observed at the ventral edge of the dorsolateral corner of the SVZ (Fig. 1I). The majority of cells lining the lateral wall of the lateral ventricle, including the dorsolateral SVZ, were derived from the Gsh2 domain (Fig. $1 F, K, L$ ). Together with the previous result, this indicates that most of the lateral wall cells are descendants of the LGE, as previously thought (see Introduction). However, we also observed a significant population of GFP-labeled SVZ cells in the Emx1-Cre/R26-GFP mice. These were found in the roof of the lateral ventricle and in the dorsolateral corner of the SVZ (Fig. $1 G, M)$.

The Emx1-derived SVZ cells were found mainly in the dorsal half of the dorsolateral corner of the SVZ (Fig. 1M), suggesting that they were genuine descendants of the embryonic cortical VZ, not Gsh2-derived cells that had upregulated Emx1 postnatally and consequently recombined de novo in the adult. We tested this directly by inducing transient recombination in Emx1-CreER ${ }^{T 2}$, R26-YFP mice with a single dose of tamoxifen at E10.5 and after the subsequent fates of labeled cells in the adult brain. The distribution of GFP-positive cells within the SVZ of pulse-labeled Emx1-CreER $R^{T 2} / R 26-Y F P$ mice (Fig. $1 N$ ) was similar to the constitutive Emx1-Cre/R26-YFP mice (Fig. 1M). These data demonstrate that cells from the embryonic cortex do indeed give rise to the dorsal and dorsolateral edge of the adult SVZ. Therefore, we conclude that the adult SVZ is comprised of cells derived predominantly from the VZ of the embryonic LGE and cortex (Fig. $1 O)$ and that the location of these cells potentially defines germi- nal domains in the SVZ similar to those known to exist developmentally.

Multipotent, self-renewing SVZ stem cells are descended from both the LGE and cortex

To determine whether SVZ cells derived from both Gsh2- and Emx1-expressing embryonic territories continue to divide in the adult SVZ, as would be expected for stem or progenitor cells, we asked whether they can incorporate BrdU in vivo. Adult Cre/R26-GFP mice were given a dose of BrdU every $6 \mathrm{~h}$ for $24 \mathrm{~h}$ and analyzed $3 \mathrm{~h}$ after the final dose. Double immunolabeling for GFP and BrdU detected small numbers of $N k x 2.1$ (MGE)-derived cells in the lateral wall of the SVZ that were BrdU positive (Fig. 2A,B). The majority of BrdU-positive cells in the SVZ were derived from Gsh2-expressing territories (Fig. 2C,D), so most proliferative SVZ cells have their origins within the LGE. A significant number of BrdU-labeled cells in the dorsolateral corner of the SVZ were Emx1 derived (Fig. $2 E, F$ ), confirming that the embryonic cortex also contributes proliferative cells to the adult SVZ. These could be either multipotent stem cells or neural progenitor cells with more restricted potential.

To investigate the stem and/or progenitor cell nature of the Emx1- and Gsh2-derived SVZ cells, we turned to cell culture assays. The adult SVZ was dissected from Cre/R26-GFP mice and dissociated to generate neurosphere cultures (see Materials and Methods). Because each neurosphere was derived from a single proliferating cell in the starting culture, each sphere was either entirely positive or entirely negative for GFP (Fig. $3 A$ ). The proportions of GFP-positive and GFP-negative neurospheres were determined for each of our Cre lines. The majority of neurosphere-forming cells in the SVZ were of striatal origin; $\sim 70 \%$ of all neurospheres were GFP positive in cultures from Gsh2-Cre/R26-GFP mice (Fig. 3B). In comparison, Emx1-derived SVZ cells accounted for $\sim 20 \%$ of the neurosphere-forming activity (Fig. 3B). Some $N k x 2.1$-derived neurospheres were detected but their contribution was small, in keeping with the low contribution of the Nkx2.1-expressing VZ to the adult SVZ (see above). All SVZ neurosphere-forming activity could be accounted for by the combination of Gsh2-derived (LGE plus MGE) and Emx1/Dbx1-derived (cortex plus corticostriatal sulcus) SVZ cells (Fig. $3 B$ ). These data provide clear evidence that the neurosphere-forming SVZ cells are heterogeneous in origin.

Neurospheres derived from Gsh2-Cre, Emxl-Cre, and Emxl/ Dbx1-Cre mice could be serially passaged more than seven times while remaining GFP positive, confirming the presence of selfrenewing stem cells (data not shown). Moreover, cultures from each of these Cre mice contained GFP-positive neurospheres that were able to generate GFAP-positive astrocytes, O4-positive oligodendrocytes, and $\beta$ III-tubulin-positive neurons when transferred to differentiation conditions, confirming their multipotency in vitro (see Materials and Methods) (Fig. 3C). However, the Nkx2.1-derived neurospheres were less neurogenic than the 
others, because a smaller proportion of GFP-positive neurospheres generated $\beta$ III-tubulin-positive neurons (Fig. $3 D$ ).

To quantify the proportions of true SVZ stem cells descended from different regions of the embryonic $\mathrm{VZ}$, we dissociated SVZ cells from R26-GFP reporter mice carrying Nkx2.1-Cre, Gsh2-Cre, Emx1-Cre, or Emx1/Dbx1-Cre and plated them in a mitogen-containing collagen matrix. Neural progenitor cells with limited self-renewing capacity formed small colonies and stopped proliferating after 1-2 weeks, whereas self-renewing stem cells continued to proliferate for $>3$ weeks, forming colonies $\geq 2 \mathrm{~mm}$ in diameter. Stem cell colonies that were GFP positive (Fig. $3 E, F$ ) and others that were GFP negative (Fig. $3 G, H$ ) were identified in all cultures after 3 weeks (Fig. 3I). The proportions of self-renewing SVZ stem cells contributed from each embryonic territory, as judged by this collagen matrix assay, were not the same as the proportions of neurosphere-forming cells measured previously. The embryonic LGE (Gsh2Cre) provided $\sim 70 \%$ of the neurosphereforming cells but only $\sim 40 \%$ of the selfrenewing stem cells, whereas the cortex (including corticostriatal sulcus, Emx1/ Dbx1-Cre) provided only $\sim 25 \%$ of the neurosphere-forming cells but $\sim 50 \%$ of the self-renewing stem cells (Fig. $3 B, I$ ). This suggests that LGE-derived adult SVZ cells might contribute a greater proportion of the transit amplifying cells and RMS neuroblasts in vivo.

\section{LGE- and cortex-derived stem cells make neurons in the adult olfactory bulb}

Adult SVZ stem cells have been identified as a subtype of subependymal astrocytes ("B cells"), because they express GFAP in vivo. We confirmed that a subset of GFP-labeled adult SVZ cells were also GFAP positive in $R 26-G F P$ reporter mice carrying either Gsh2-Cre or Emx1-Cre (Fig. 4A,B). There were also small numbers of cells colabeled for GFP and GFAP in Nkx2.1-Cre/ R26-GFP mice (data not shown). To visualize migratory neuroblasts, we immunolabeled each transgenic to detect GFP expression and either Doublecortin (Dcx) or PSA-NCAM. Dcx- and PSA-NCAM-positive neuroblasts in the SVZ and RMS were detected only in the Gsh2-Cre and Emx1-Cre transgenics, indicating that the LGE- and cortex-derived stem cells are responsible for most or all olfactory neurogenesis in the adult (Fig. 4D, E; PSANCAM shown). Equivalent immunohistochemical analysis of the SVZ of adult Emx1-creER $R^{T 2} / R 26-Y F P$ mice (Fig. 4C,F), induced at E10.5, produced a similar staining pattern to that of the adult Emx1-cre/R26-GFP, confirming that stem cells originating in the embryonic cortex and retained in the adult SVZ generate neuroblasts throughout life.

To determine directly the separate contributions of Nkx2.1-, Gsh2-, Dbx1-, and Emx1-derived stem cells to olfactory neurogenesis, we mapped GFP-labeled cells within the adult olfactory bulbs of our Cre/R26-GFP mice. GFP-positive cells were detected
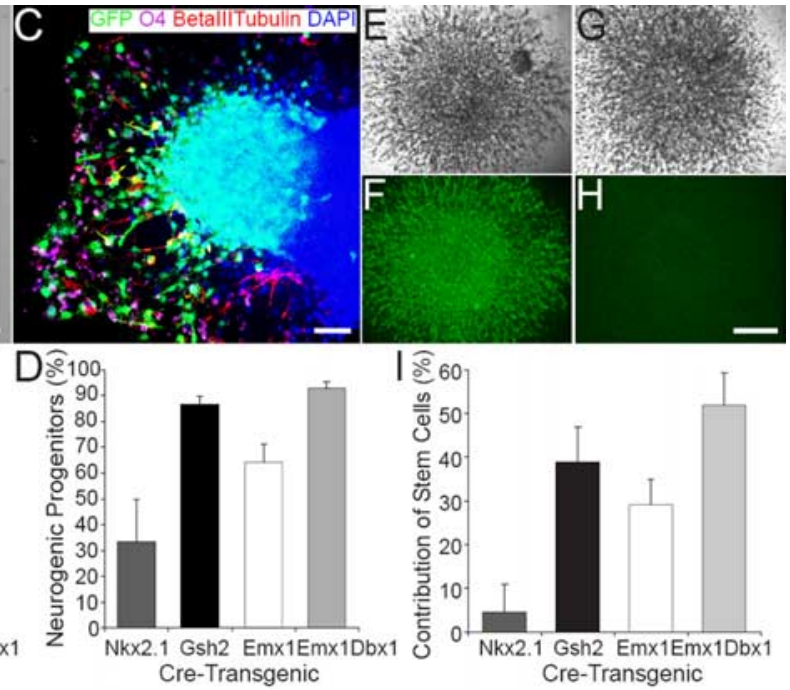

Cre-Transgenic

Cre-Transgenic

Figure 3. All regions of the embryonic neuroepithelium give rise to multipotent, self-renewing stem cells in the adult SVZ. $\boldsymbol{A}$, Neurosphere cultures were generated from the SVZ of adult R26-GFP reporter mice carrying Nkx2.1-Cre, Gsh2-Cre, or Emx1-Cre transgenes, or both Emx1- and Dbx1-Cre together. Individual neurospheres were either uniformly GFP positive or negative, replated under differentiation-inducing conditions for $5 \mathrm{~d}$ before being fixed and triple-immunolabeled with anti-GFP (green), (

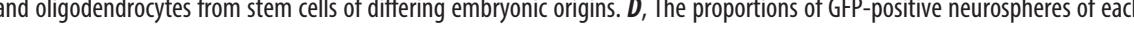
I-Cre/R26-GFP culture. $I$, The proportions of GFP-positive stem cell colonies of each genotype are shown graphically. Scale bars: $\boldsymbol{A}, 100 \mu \mathrm{m} ; \boldsymbol{C}, 25 \mu \mathrm{m} ; \boldsymbol{E}-\boldsymbol{H}, 0.5 \mathrm{~mm}$.

in the granule cell layer ( $\mathrm{gcl})$, mitral cell layer $(\mathrm{mcl})$, external plexiform layer (epl), and glomerular layer (gl) of R26-GFP reporters carrying the Nkx2.1-Cre, Gsh2-Cre, or Emx1-Cre transgenes (Fig. 5A-C) as well as the Emx1/Dbx1-Cre/R26-GFP tripletransgenic (data not shown). Most of the GFP-labeled cells represent olfactory bulb cells that were generated during embryonic or early postnatal development, as opposed to adult-born cells. To identify SVZ-derived cells that migrated into the olfactory bulb during adulthood, we administered BrdU at P50 and examined the olfactory bulbs 4 weeks later. Only $\sim 1 \%$ of all BrdU-positive cells were $N k x 2.1$ derived (Fig. 5D,H). The majority $(\sim 70 \%)$ were $G s h 2$ derived (Fig. $5 E, H)$, indicating that most adult-born cells in the olfactory bulb are generated from LGE-derived stem cells. Approximately $30 \%$ of BrdU-labeled olfactory bulb neurons were $E m x-1$ derived (Fig. $5 F, H$ ). No additional contribution was observed in Emx1/Dbx1-Cre/R26-GFP mice (Fig. 5G,H), indicating that $D b x 1$-derived cells do not generate significant numbers of adult olfactory cells.

\section{LGE- and cortex-derived adult SVZ stem cells have different properties}

Gsh2- and Emx1-derived cells were found in all layers of the olfactory bulb, although there was a relatively higher contribution of Emx1-derived cells to the glomerular layer than the granule cell layer (Fig. $5 \mathrm{~K}$ ). To investigate whether this laminar bias might result from different cell fate specificities of Gsh2- and Emx1- 

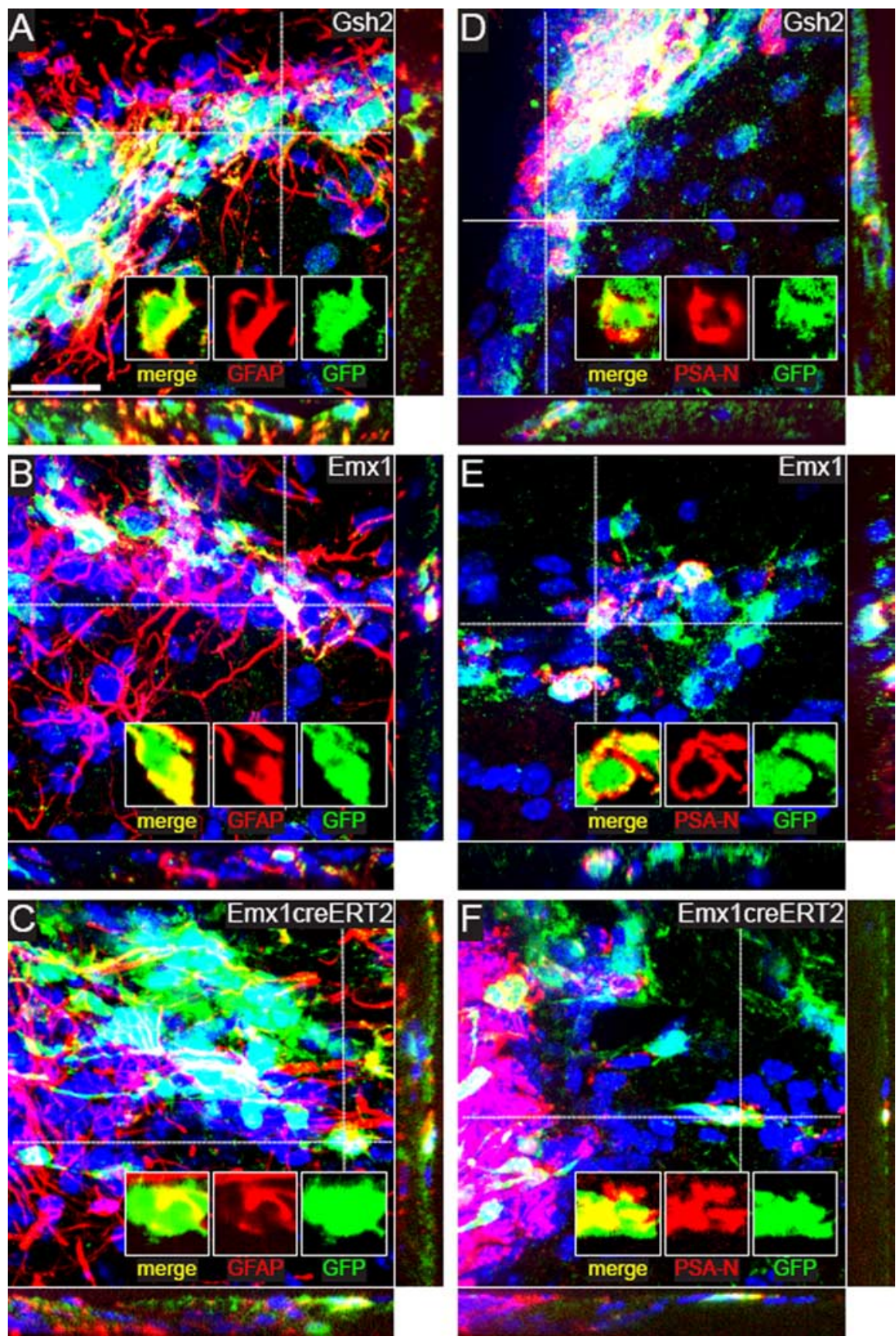

Figure 4. Cortex- and LGE-derived SVZ stem cells generate new neuroblasts in vivo. Coronal sections through the forebrain of R26-GFP reporters carrying either the Gsh2-Cre $(\boldsymbol{A}, \boldsymbol{D}), \operatorname{Emx1} 1-\operatorname{Cre}(\boldsymbol{B}, \boldsymbol{E})$, or Emx1-CreER ${ }^{T 2}(\boldsymbol{C}, \boldsymbol{F})$ transgene were double immunolabeled for GFP (green) together with either GFAP (red; to identify multipotent stem cells) ( $\boldsymbol{A}-\boldsymbol{C})$ or PSA-NCAM (red; to identify neuroblasts) (D-F). All sections were counterstained with Hoechst nuclear dye (blue). Images show the dorsolateral corner of the SVZ (compressed confocal series with orthogonal views taken at the level indicated by the dashed line). GFAP-positive stem cells and PSANCAM-positive neuroblasts descend from both the embryonic LGE and cortex (single confocal scan inset). Scale bar, $30 \mu \mathrm{m}$.

Cre backgrounds) suggesting that this population is not turned over significantly in the adult. Parvalbumin-positive neurons had dual developmental origins, with some cells coexpressing YFP in both the Emx1-Cre and Gsh2-Cre transgenics (Fig. $7 A, B)$.

Tyrosine hydroxylase-positive, BrdUpositive neurons were detected in the glomerular layer. These adult-born tyrosine hydroxylase-positive interneurons were generated from both LGE- and cortexderived SVZ stem cells (Fig. 7C,D,I) in numbers proportional to the overall contributions of these stem cell pools to the olfactory bulb $(\sim 70$ and $\sim 30 \%$, respectively) (Figs. 5H, 7I) and similar to their neurosphere-forming activities in vitro (Fig. $3 B$ ). These data suggest that LGEand cortex-derived neuroblasts are equally likely to generate tyrosine hydroxylasepositive (dopaminergic) interneurons.

The situation was different for calretinin-positive, adult-born neurons, the majority of which $(\sim 60 \%)$ were generated from cortex-derived $(E m \times 1)$ stem cells (Fig. 7E, F,I), despite the fact that cortex-derived SVZ stem cells generate only $\sim 30 \%$ of the total (Fig. $5 H$ ). This was the first indication that LGE-derived and cortex-derived stem cell progeny might have differential cell fates. This conclusion was strikingly reinforced when we immunolabeled for calbindin. We found that, although there were far fewer new adultborn calbindin-expressing interneurons generated in the olfactory glomeruli relative to calretinin $(\sim 10-15 \%)$, they were all produced by LGE-derived SVZ stem cells, and none from their cortex-derived counterparts (Fig. 7G-I). Interestingly $88 \pm 6 \%$ of all calbindin-positive olfactory interneurons present at P80 were generated from striatum (Gsh2)-derived progeny (calbindin and GFP double-positive) (Fig. $7 J$ ). In comparison, only $1.5 \pm 0.8 \%$ of calbindin-positive interneurons appeared to be GFP positive in Emx1-Cre/ R26-GFP mice (Fig. 7K) (for experimental details, see Materials and Methods, Immunocytochemistry). For further confirmation that embryonic cortex-derived cells fail to generate calbindin-positive olfac-

derived stem cells, we categorized their adult-born (BrdUpositive) neuronal progeny by immunolabeling for parvalbumin (PV), tyrosine hydroxylase (TH), calretinin (Crt), or calbindin (Cb). The locations and connections of olfactory bulb neurons that express these markers are illustrated in Figure 6.

BrdU was administered at 7 weeks of age, and the olfactory bulbs were analyzed 4 weeks later (P80) as before. Parvalbuminpositive neurons were detected in the external plexiform layer (EPL) but were never labeled with BrdU (>100 parvalbuminlabeled cells examined in three mice of both Emx1-Cre and Gsh2- tory interneurons, we again turned to the Emx1-CreER ${ }^{T 2} / R 26-$ YFP transgenic line. Tamoxifen was administered at E10.5 and the olfactory bulbs were examined at P50. This experiment confirmed that descendants of embryonic cortical precursors included significant numbers of tyrosine hydroxylase- and calretinin-positive interneurons but very few calbindin-positive interneurons (Fig. $7 L-N$ ). Collectively, these data strongly support the idea that cortex-derived and striatum-derived precursor/stem cells remain functionally distinct throughout life, generating different subsets of olfactory neurons during development and even in the adult. 
Tamoxifen was also administered to adult Emx1-CreER ${ }^{T 2} / R 26-Y F P$ transgenic mice ( $\sim$ P50), allowing us to label and trace the descendants of any stem or progenitor cells that continue to express Emx 1 into adulthood. Animals were analyzed at different times after tamoxifen induction to follow the progress of YFP-labeled cells from the SVZ to the olfactory bulb. At 1 week after induction, the shortest time lag examined, YFP-positive cells were observed in the dorsal part of the adult SVZ and the proximal end of the RMS. The location of these cells within the SVZ was consistent with the restricted location of cortex-derived progeny reported previously (Fig. $1 M, N$ ). The GFP-positive cells identified were also GFAP positive (Fig. $8 A, B$ ). By 4 weeks after induction (YFP, GFAP) double-positive cells were still present in the SVZ (Fig. 8C), and in addition, there were clusters of GFP-positive cells that were GFAP negative (Fig. 8D). Some of these cells were Dcx-positive neuroblasts. Other YFP-positive, Dcxnegative cells were observed on the dorsal edge of the SVZ and in the corpus callosum (data not shown).

The olfactory bulb was devoid of YFPpositive cells at short times after tamoxifen induction, as expected if they migrate into the bulb from the SVZ via the RMS (Fig. $8 E$ ). After 4 weeks, both (YFP, PSANCAM) double-positive neuroblasts and (YFP, NeuN) double-positive neurons could be found in the granule cell layer (Fig. $8 F, G$ ) and the glomerular layer (data not shown). The number of YFP-labeled cells in the olfactory bulb remained small because of the inefficiency of tamoxifen induction in adulthood. However, there were some cells that colabeled for YFP and calretinin in the granule cell layer (Fig. $8 \mathrm{H}$ ) and the glomerular layer (data not shown). None of $>250$ YFP-positive cells that we examined coexpressed calbindin, reinforcing the results obtained with constitutive Emx1-Cre/R26-YFP mice and $\operatorname{BrdU}$ (Fig. $7 H, K$ ). The fact that the Emx1$\mathrm{CreER}^{T 2}$ transgene remains active in the adult implies that cortex-derived SVZ stem cells continue to express Emx1 into adulthood. In addition, the YFP-positive cells detected in the SVZ of Emx1-Cre/R26-YFP mice never immunolabeled for Gsh2 (supplemental Fig. S1, available at www.jneurosci.org as supplemental material). Therefore, we conclude that the different SVZ stem cell pools not only have different embryonic origins but also different molecular properties and different neurogenic fates in the adult olfactory bulb.

\section{Discussion}

The main findings of this study are as follows: (1) the adult SVZ contains stem cells derived from multiple regions of the embryonic neuroepithelium (MGE, LGE, and cortex), (2) stem cells
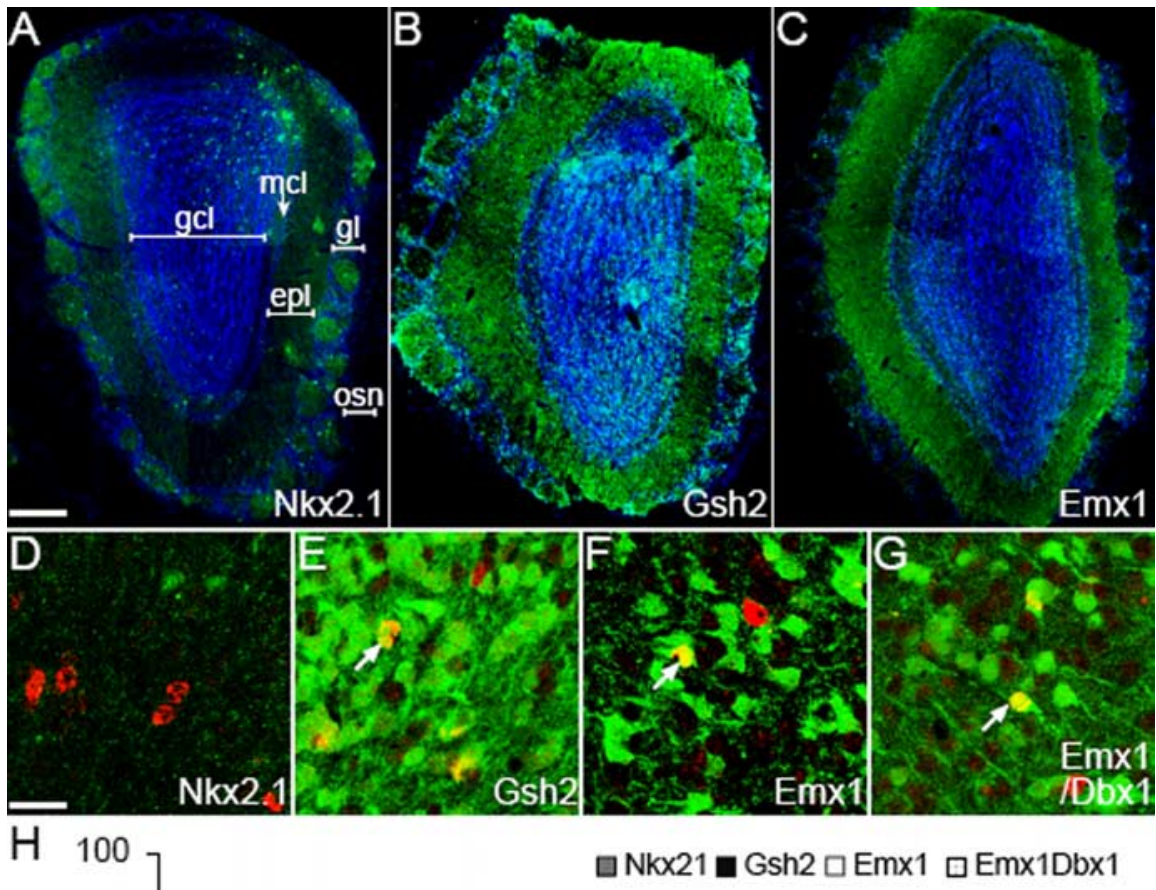

Figure 5. LGE- and cortex-derived stem cells give rise to new cells in the adult olfactory bulb. Thirty micrometer coronal sections through the olfactory bulb of adult R26R-GFP reporter mice carrying Nkx2.1-Cre, Gsh2-Cre, or Emx1-Cre transgenes were immunolabeled for GFP $(\boldsymbol{A}-\boldsymbol{C})$. To identify newly generated cells, we injected BrdU at P50 and analyzed the olfactory bulb $30 \mathrm{~d}$ later (P80) for the presence of (GFP, BrdU) double-positive cells. Colabeled cells were rarely detected in Nkx2.1-Cre/R26-GFP olfactory bulbs $(\boldsymbol{D}, \boldsymbol{H})$. However, many (GFP, BrdU) double-positive cells were present in Gsh2-Cre/R26-GFP, Emx1-Cre/R26-GFP, and $E m \times 1 / D b x 1-C r e / R 26-G F P$ olfactory bulbs (E-G, arrows). The proportions of newly born adult cells were quantified according to genotype for the entire olfactory bulb $(O B)$ and separately for the granule cell layer $(\mathrm{gcl})$ ), mitral cell layer (mcl), external plexiform layer (epl), and glomerular layer ( $\mathrm{gl}$ ) (see $\boldsymbol{A})$. There is laminar variation in the relative proportions of Gsh2- and Emx1-derived adult-born cells. For experimental details, see Materials and Methods, Immunocytochemistry. Scale bars: $\boldsymbol{A}-\boldsymbol{C}, 200$ $\mu \mathrm{m} ; \boldsymbol{D}-\mathbf{G}, 20 \mu \mathrm{m}$. Error bars indicate SD. osn, Olfactory sensory neurons.

from both the LGE and cortex contribute to adult neurogenesis in the olfactory bulb, and (3) cortical and LGE-derived stem cells are distinct populations with regard to their distribution within the SVZ, their molecular properties, and their behavior, because they make nonproportional contributions to the genesis of olfactory interneuron subtypes.

\section{SVZ stem cells are heterogeneous in origin and behavior}

Previous evidence had suggested a purely striatal origin for adult SVZ stem cells (Stenman et al., 2003). However, we show here that the LGE contributes most but not all neurosphere-forming cells and less than one-half of the self-renewing stem cells, the remainder originating mainly from the embryonic cortex (Emx1- 


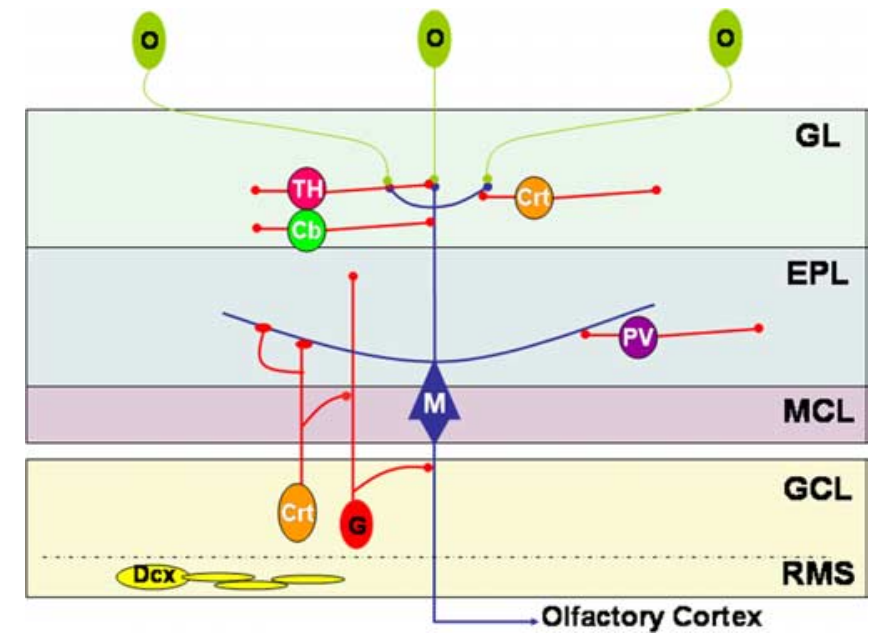

Figure 6. Locations and connections of interneurons in the olfactory bulb. The diagram represents a coronal section through an adult mouse olfactory bulb. New neuroblasts (DCX positive) enter the bulb from the RMS, migrate radially and differentiate as interneurons in (1) the granule cell layer (GCL), (2) the mitral cell layer (MCL), (3) the EPL, and (4) the glomerular layer (GL). Immunolabeling for calretinin (Crt), calbindin (Cb), tyrosine hydroxylase (TH), or parvalbumin (PV) identifies subpopulations of olfactory interneurons distributed throughout the bulb as shown. The majority of granule neurons $(G)$ are not identified by any of these markers. The $M C L$ also contains mitral projection neurons $(M)$, which are not replaced during adulthood from RMS neuroblasts. Olfactory sensory neurons $(0)$ in the olfactory epithelium in the nasal cavity are also not replaced by RMS neuroblasts. Adapted from Lledo et al. (2006).

plus Dbx1-domains). Our findings confirm the recent report from Willaime-Morawek et al. (2006) that cells from the embryonic cortex contribute to the neurosphere-forming cells of the adult SVZ. Our findings are also consistent with the report from Ventura and Goldman (2007) that dorsal (cortical) radial glia are stem cells that contribute interneurons to the adult olfactory bulb, in addition to astrocytes and oligodendrocytes.

Because neurosphere cultures derived from our Cre/R26-GFP transgenic mice contained neurospheres that were entirely GFP positive and others that were entirely GFP negative, it is clear that the patterns of gene expression established early in the embryo remain stable in the adult, even when the cells are dissociated and cultured at low density (that is, cells from the embryonic cortex do not activate Gsh2 expression in culture). Stability of gene expression is also supported by the fact that SVZ cells that express YFP in the Emx1-Cre/R26-YFP transgenic do not exhibit Gsh2 immunoreactivity (supplemental Fig. S1, available at www.jneurosci.org as supplemental material) and that our Emx1-CreER ${ }^{T 2}$ transgene made a similar contribution to the adult SVZ whether tamoxifen was administered in the embryo (E10.5) or in the adult (P50). We therefore presume that the adult SVZ contains distinct populations of Emx1-expressing and Gsh2-expressing stem cells (and possibly others) that have distinct and overlapping neurogenic properties.

It is known that at least three subtypes of GABAergic interneurons expressing the GABA-synthesizing enzyme glutamate decarboxylase can be identified in the periglomerular layer of the olfactory bulb. These three mostly nonoverlapping populations can be identified by their expression of calretinin, calbindin-D28K (two members of the EF-hand family of calcium-binding proteins), or tyrosine hydroxylase (dopaminergic subpopulation), and are all generated or regenerated continuously during adulthood (Kosaka et al., 1995; Dellovade et al., 1998; Hack et al., 2005; Kohwi et al., 2005). Adult-born calretinin-positive interneurons are also found in the granule neuron layer (Fig. 6). Our data confirm that these neuronal subtypes continue to be generated during adulthood. However, when we examined the turnover of interneurons expressing parvalbumin, a third calcium-binding protein of the EF-hand family, we found that these neurons, located in the EPL, are not turned over significantly during adulthood. In this sense, they resemble projection neurons such as mitral cells but differ from most olfactory interneurons. Parvalbumin-positive neurons are also present in the human olfactory bulb and these were reported to be generated continuously in the adult (Bedard and Parent, 2004). However, human parvalbumin neurons are found in the glomerular layer, not the EPL, suggesting that parvalbumin marks different populations of neurons in humans and mice. Otherwise, adult-born neurons in the human olfactory bulb include GAD65-, tyrosine hydroxlyase-, and calretinin-positive interneurons, similar to those of the mouse (Kosaka et al., 1995; Bedard and Parent, 2004).

There are stem cells that reside in the RMS throughout life, in addition to those in the SVZ (Gritti et al., 2002). Hack et al. (2005) found that the RMS stem cells generate the majority of tyrosine hydroxylase-positive interneurons in the adult olfactory bulb, the remainder coming from the SVZ. Ventura and Goldman (2007) labeled dorsal radial glia directly using an adenovirus applied to the cortical surface and showed that they generate tyrosine hydroxylase-positive periglomerular neurons as well as astrocytes and oligodendrocytes. The RMS is contiguous with the SVZ and the cortical (Emx1-expressing) neuroepithelium contributes to the development of both structures, so our own fatemapping experiments with Emx1-Cre cannot distinguish adult stem cells that reside in the RMS from those of the dorsal SVZ. Nevertheless, we too have confirmed that cortex-derived stem cells, presumably a combination of RMS and SVZ stem cells, generate tyrosine hydroxylase-positive (and calretinin-positive) olfactory interneurons in the adult.

Olfactory bulbectomy has provided evidence that interneuron cell type identity is established before neuroblasts reaching the olfactory bulb in vivo (Jankovski et al., 1998). Our data support this conclusion by demonstrating that the neurogenic properties of adult SVZ stem cells are determined very early, according to their sites of origin in the embryonic neuroepithelium. We found that LGE- and cortex-derived stem cells (whether from RMS or SVZ) generated all of the adult-born tyrosine hydroxylase interneurons in the olfactory bulb (Fig. 7I) and did so in proportion to the contributions of these stem cell populations to olfactory neurogenesis overall. However, this was not true for adult-born calretinin interneurons, most of which were generated from cortexderived SVZ stem cells, despite their being less neurogenic overall than those from the LGE. Strikingly, all of the adult-born calbindin-D28K-positive interneurons originated from LGEderived SVZ stem cells and none from cortex-derived stem cells. These data indicate that the fates of adult SVZ stem cells are already determined within the SVZ (or RMS). Together with the finding of Hack et al. (2005) that the neurogenic properties of the RMS and SVZ are distinguishable, our studies raise the possibility that some aspects of embryonic patterning along both dorsal-ventral and anterior-posterior axes are preserved in the adult SVZ.

\section{Different SVZ stem cells for different purposes?}

SVZ neural stem cells have been defined in vitro by their ability to proliferate, self-renew, and generate multipotent progeny (Richards et al., 1992; Reynolds and Weiss, 1992; Young et al., 2006, 2007). In vivo, the slowly dividing neural stem cells generate more rapidly dividing neural progenitor cells ("transit amplifying cells”), which in turn generate postmitotic neuroblasts destined 
for the olfactory bulb (Doetsch et al., 1999a,b). Transit amplifying cells and neural stem cells are both capable of generating neurospheres (Doetsch et al., 2002), so, in addition to neurosphere assays, we cultured SVZ cells in a semisolid collagen matrix to identify the true stem cells, which proliferate longer and form larger colonies than transit-amplifying cells. We found that the numbers of stem cells and neurosphere-forming cells were not in proportion to one another. For example, the LGE contributed a greater proportion of neurosphere-forming cells than stem cells ( $\sim 70$ vs $\sim 40 \%$ of the total), whereas for the cortex (Emx1 plus Dbx1 domains) the opposite was true ( $\sim 30$ vs $\sim 50 \%$ ). These data suggest that LGEderived stem cells might be more active in generating transit-amplifying cells for the RMS than their cortex-derived counterparts. It is also worth noting that, whereas the embryonic $D b x 1$-expressing domain at the lateral edges of the cortex appears to contribute $\sim 20 \%$ of the in vitro stem cell activity of the SVZ (Fig. 3I), this domain did not contribute significant numbers of adult born olfactory cells in vivo (Fig. $5 H$ ). Therefore, the Dbx1-derived stem cells might serve some function other than olfactory neurogenesis, perhaps contributing preferentially to adult gliogenesis, another known function of the postnatal SVZ (Levison and Goldman, 1993; Luskin and McDermott, 1994; Menn et al., 2006). Alternatively, they might lie dormant until activated after an ischemic insult or other CNS damage (Magavi et al., 2000; PicardRiera et al., 2002; Sundholm-Peters et al., 2005) or in response to a physiological stimulus (Shingo et al., 2003).

\section{Cell fate determinants in the SVZ and RMS}

We have taken advantage of the spatially restricted embryonic expression of several transcription factors to show that embryonic origin is important for the future properties of adult stem cells and their progeny. This was highlighted by our examining the origin of calbindin-positive olfactory interneurons. The great majority of these cells are generated during early postnatal development (DeMarchis et al., 2007) from striatum-derived precursor cells (this study). Smaller numbers of calbindin-positive interneurons are generated continuously during adult life, and these are all derived from striatum-derived SVZ stem cells. In contrast, the cortex made an insignificant contribution to the genesis of calbindinpositive interneurons at any stage of development or in the adult. It therefore seems likely that the transcription factors we used to demarcate the embryonic stem cell domains (Gsh2 and Emx1) (and possibly others) remain active in adult stem cells and play a role in restricting their subsequent cell fates. It is known that Emxl has an important function in olfactory behavior (Cao and
$\mathrm{Li}, 2002)$. Other transcription factors that have been detected in the SVZ and/or RMS include Pax6 (Hack et al., 2005; Kohwi et al., 2005), Mash1 (Kohwi et al., 2005), Dlx2 (Doetsch et al., 2002), Olig2 (Parras et al., 2004; Hack et al., 2005), Er81 (Stenman et al., 2003), and Sp8 (Waclaw et al., 2006). Sp8 is retained in calretininexpressing and nondopaminergic GABAergic interneurons of the glomerular layer. It will be interesting to determine whether any of these transcription factors or specific combinations of them are expressed in subsets of neuroblasts that can be traced back specifically to either LGE- or cortex-derived SVZ stem cells.

Our demonstration that striatum-derived and cortex-derived stem cells generate distinct subsets of olfactory interneurons in the adult, together with evidence that they are spatially and developmentally distinct populations, indicates that adult SVZ 


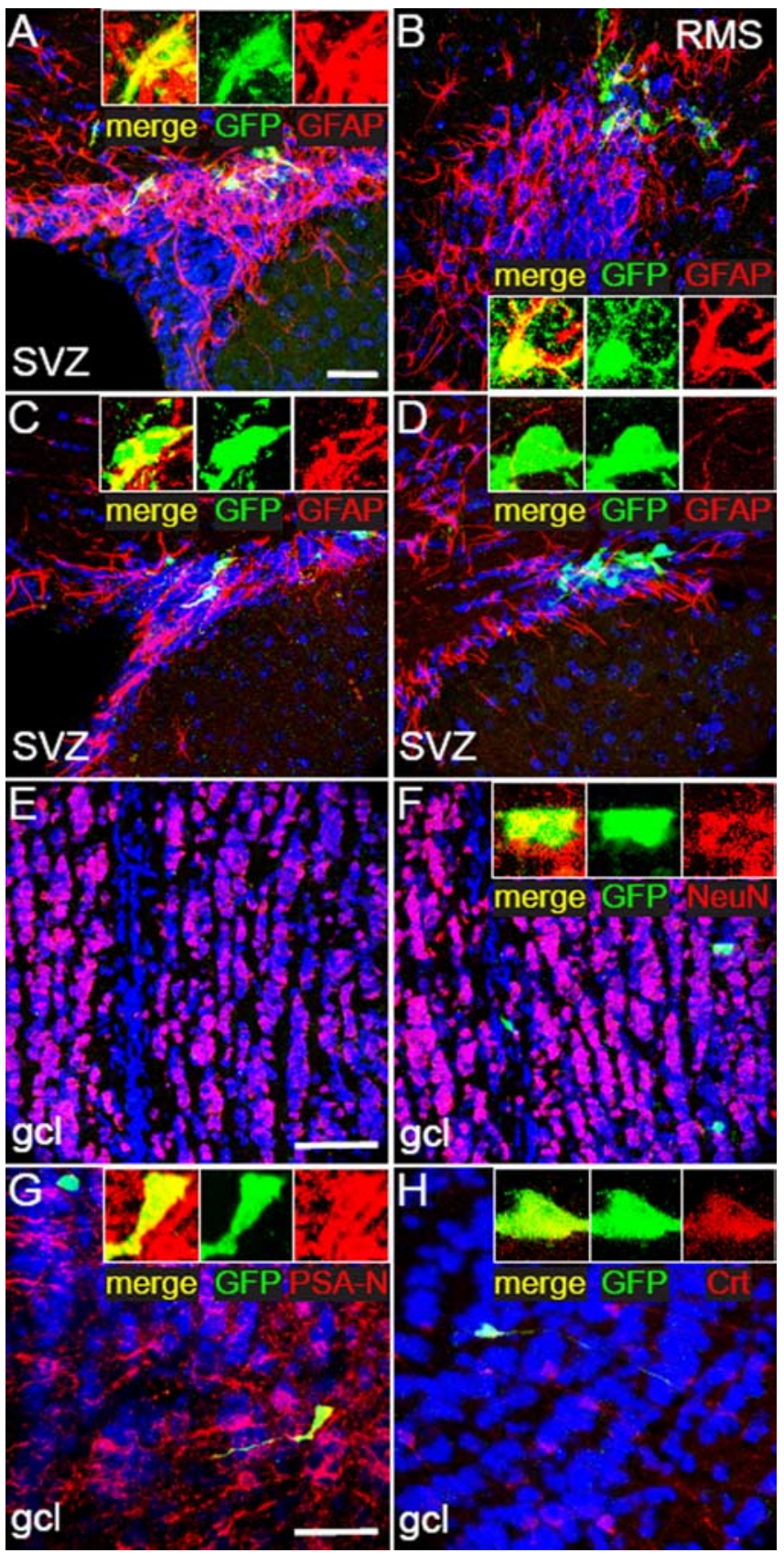

Figure 8. A population of adult SVZ stem cells expresses $E m \times 1$ into adulthood. Tamoxifen was administered to young adult (7 weeks of age) Emx1-CreER ${ }^{T 2} / R 26-Y F P$ transgenic mice. After 1 week $(\boldsymbol{A}, \boldsymbol{B})$ or 6 weeks $(\boldsymbol{C}, \boldsymbol{D})$, brain sections were double immunolabeled for YFP (green) together with GFAP (red) to label stem cells in the SVZ $(\boldsymbol{A}, \boldsymbol{C}, \boldsymbol{D})$ or proximal RMS (B). Sections were counterlabeled with Hoechst nuclear stain (blue). (YFP, GFAP) Double-positive stem cells were present at both 1 and 6 weeks after tamoxifen. YFP-single-positive presumptive neuroblasts were also present at 6 weeks (D). No YFP-labeled neurons (NeuN-positive) were present in the olfactory bulb at 1 week after tamoxifen $(\boldsymbol{E})$, but small numbers were found at 6 weeks $(\boldsymbol{F})$. At 6 weeks after tamoxifen, (YFP, PSA-NCAM) double-positive neuroblasts and (YFP, calretinin) double-positive interneurons were also present $(\boldsymbol{G}, \boldsymbol{H})$. High-magnification images of representative cells are shown as insets (single confocal scans). These data are consistent with the interpretation that Emx1-positive stem cells in the SVZ generate neuroblasts that migrate via the RMS into the olfactory bulb and differentiate as olfactory interneurons. Scale bars, $50 \mu \mathrm{m}$.

stem cells are nonuniform with respect to their cellular properties and behavior. This is potentially an important consideration when attempting to harness endogenous neural stem cells for therapy or repair.

\section{References}

Alvarez-Buylla A, Lim DA (2004) For the long run: maintaining germinal niches in the adult brain. Neuron 41:683-686.

Anthony TE, Klein C, Fishell G, Heintz N (2004) Radial glia serve as neuronal progenitors in all regions of the central nervous system. Neuron 41:881-890.

Bedard A, Parent A (2004) Evidence of newly generated neurons in the human olfactory bulb. Brain Res Dev Brain Res 151:159-168.

Bull ND, Bartlett PF (2005) The adult mouse hippocampal progenitor is neurogenic but not a stem cell. J Neurosci 25:10815-10821.

Cao BJ, Li Y (2002) Reduced anxiety- and depression-like behaviors in Emx1 homozygous mutant mice. Brain Res 937:32-40.

Dellovade TL, Pfaff DW, Schwanzel-Fukuda M (1998) Olfactory bulb development is altered in small-eye (Sey) mice. J Comp Neurol 402:402-418

DeMarchis S, Bovetti S, Carletti B, Hsieh YS, Garzotto D, Peretto P, Fasolo A, Puche AC, Rossi F (2007) Generation of distinct types of periglomerular olfactory bulb interneurons during development and in adult mice: implication for intrinsic properties of the subventricular zone progenitor population. J Neurosci 27:657-664.

Doetsch F (2003) A niche for adult neural stem cells. Curr Opin Genet Dev 13:543-550

Doetsch F, Caille I, Lim DA, Garcia-Verdugo JM, Alvarez-Buylla A (1999a) Subventricular zone astrocytes are neural stem cells in the adult mammalian brain. Cell 97:703-716.

Doetsch F, Garcia-Verdugo JM, Alvarez-Buylla A (1999b) Regeneration of a germinal layer in the adult mammalian brain. Proc Natl Acad Sci USA 96:11619-11624

Doetsch F, Petreanu L, Caille I, Garcia-Verdugo JM, Alvarez-Buylla A (2002) EGF converts transit-amplifying neurogenic precursors in the adult brain into multipotent stem cells. Neuron 36:1021-1034.

Fogarty M, Richardson WD, Kessaris N (2005) A subset of oligodendrocytes generated from radial glia in the dorsal spinal cord. Development 132:1951-1959.

Gage FH (2000) Mammalian neural stem cells. Science 287:1433-1438.

Gritti A, Bonfanti L, Doetsch F, Caille I, Alvarez-Buylla A, Lim DA, Galli R, Verdugo JMG, Herrera DG, Vescovi AL (2002) Multipotent neural stem cells reside into the rostral extension and olfactory bulb of adult rodents. J Neurosci 22:437-445.

Hack MA, Saghatelyan A, de Chevigny A, Pfeifer A, Shery-Padan R, Lledo PM Götz M (2005) Neuronal fate determinants of adult olfactory bulb neurogenesis. Nat Neurosci 8:865-872.

Jankovski A, Garcia C, Soriano E, Sotelo C (1998) Proliferation, migration and differentiation of neuronal progenitor cells in the adult mouse subventricular zone surgically separated from its olfactory bulb. Eur J Neurosci 10:3853-3868.

Kessaris N, Fogarty M, Iannarelli P, Grist M, Wegner M, Richardson WD (2006) Competing waves of oligodendrocytes in the forebrain and postnatal elimination of an embryonic lineage. Nat Neurosci 9:173-179.

Kohwi M, Osumi N, Rubenstein JL, Alvarez-Buylla A (2005) Pax6 is required for making specific subpopulations of granule and periglomerular neurons in the olfactory bulb. J Neurosci 25:6997-7003.

Kosaka K, Aika Y, Toida K, Heizmann CW, Hunziker W, Jacobowitz DM, Nagatsu I, Streit P, Visser TJ, Kosaka T (1995) Chemically defined neuron groups and their subpopulations in the glomerular layer of the rat main olfactory bulb. Neurosci Res 23:73-88.

Kriegstein AR, Götz M (2003) Radial glia diversity: a matter of cell fate. Glia 43:37-43.

Laywell ED, Rakic P, Kukekov VG, Holland EC, Steindler DA (2000) Identification of a multipotent astrocytic stem cell in the immature and adult mouse brain. Proc Natl Acad Sci USA 97:13883-13888.

Levison SW, Goldman JE (1993) Both oligodendrocytes and astrocytes develop from progenitors in the subventricular zone of postnatal rat forebrain. Neuron 10:201-212.

Lledo P-M, Alonso M, Grubb MS (2006) Adult neurogenesis and functional plasticity in neuronal circuits. Nat Rev Neurosci 7:179-193.

Luskin MB, McDermott K (1994) Divergent lineages for oligodendrocytes and astrocytes originating in the neonatal forebrain subventricular zone. Glia 11:211-226.

Magavi SS, Leavitt BR, Macklis JD (2000) Induction of neurogenesis in the neocortex of adult mice. Nature 405:951-955.

Malatesta P, Hack MA, Hartfuss E, Kettenmann H, Klinkert W, Kirchhoff F, 
Gotz M (2003) Neuronal or glial progeny: regional differences in radial glia fate. Neuron 37:751-764.

Mao X, Fujiwara Y, Chapdelaine A, Yang H, Orkin SH (2001) Activation of EGFP expression by Cre-mediated excision in a new ROSA26 reporter mouse strain. Blood 97:324-326.

Menn B, Garcia-Verdugo JM, Yaschine C, Gonzalez-Perez O, Rowitch D, Alvarez-Buylla A (2006) Origin of oligodendrocytes in the subventricular zone of the adult brain. J Neurosci 26:7907-7918.

Merkle FT, Tramontin AD, Garcia-Verdugo JM, Alvarez-Buylla A (2004) Radial glia give rise to adult neural stem cells in the subventricular zone. Proc Natl Acad Sci USA 101:17528-17532.

Morshead CM, van der Kooy D (2004) Disguising adult neural stem cells. Curr Opin Neurobiol 14:125-131.

Noctor SC, Flint AC, Weissman TA, Wong WS, Clinton BK, Kriegstein AR (2002) Dividing precursor cells of the embryonic cortical ventricular zone have morphological and molecular characteristics of radial glia. J Neurosci 22:3161-3173.

Parmar M, Sjoberg A, Bjorklund A, Kokaia Z (2003) Phenotypic and molecular identity of cells in the adult subventricular zone in vivo and after expansion in vitro. Mol Cell Neurosci 24:741-752.

Parras CM, Galli R, Britz O, Soares S, Galichet C, Battiste J, Johnson JE, Nakafuku M, Vescovi A, Guillemot F (2004) Mash1 specifies neurons and oligodendrocytes in the postnatal brain. EMBO J 23:4495-4505.

Picard-Riera N, Decker L, Delarasse C, Goude K, Nait-Oumesmar B, Liblau R, Pham-Dinh D, Evercooren AB (2002) Experimental autoimmune encephalomyelitis mobilizes neural progenitors from the subventricular zone to undergo oligodendrogenesis in adult mice. Proc Natl Acad Sci USA 99:13211-13216.

Reynolds BA, Weiss S (1992) Generation of neurons and astrocytes from isolated cells of the adult mammalian central nervous system. Science 255:1707-1710.

Richards LJ, Kilpatrick TJ, Bartlett PF (1992) De novo generation of neuro- nal cells from the adult mouse brain. Proc Natl Acad Sci USA 89:8591-8595.

Shingo T, Gregg C, Enwere E, Fujikawa H, Hassam R, Geary C, Cross JC, Weiss S (2003) Pregnancy-stimulated neurogenesis in the adult female forebrain mediated by prolactin. Science 299:117-120.

Srinivas S, Watanabe T, Lin CS, William CM, Tanabe Y, Jessell TM, Costantini F (2001) Cre reporter strains produced by targeted insertion of EYFP and ECFP into the ROSA26 locus. BMC Dev Biol 1:4.

Stenman J, Toresson H, Campbell K (2003) Identification of two distinct progenitor populations in the lateral ganglionic eminence: implications for striatal and olfactory bulb neurogenesis. J Neurosci 23:167-174.

Sundholm-Peters NL, Yang HK, Goings GE, Walker AS, Szele FG (2005) Subventricular zone neuroblasts emigrate toward cortical lesions. J Neuropathol Exp Neurol 64:1089-1100.

Tamamaki N (2005) Origin of the neocortical subependymal cells speculated by Emx1 and GAD67 expression. Chem Senses 30:111-112.

Ventura RE, Goldman JE (2007) Dorsal radial glia generate olfactory bulb interneurons in the postnatal murine brain. J Neurosci 27:4297-4302.

Waclaw RR, Allen ZJ, Bell SM, Erdelyi F, Szabo G, Potter SS, Campbell K (2006) The zinc finger transcription factor Sp8 regulates the generation and diversity of olfactory bulb interneurons. Neuron 49:503-516.

Willaime-Morawek S, Seaberg RM, Batista C, Labbe E, Attisano L, Gorski JA, Jones KR, Kam A, Morshead CM, van der Kooy D (2006) Embryonic cortical neural stem cells migrate ventrally and persist as postnatal striatal stem cells. J Cell Biol 175:159-168.

Young KM, Bartlett PF, Coulson EJ (2006) Neural progenitor number is regulated by nuclear factor-kappaB p 65 and p 50 subunit-dependent proliferation rather than cell survival. J Neurosci Res 83:39-49.

Young KM, Merson TD, Sotthibundhu A, Coulson EJ, Bartlett PF (2007) p75 neurotrophin receptor expression defines a population of BDNFresponsive neurogenic precursor cells. J Neurosci 27:5146-5155. 